\title{
MURCHA-BACTERIANA: DISSEMINAÇÃO DO PATÓGENO E EFEITOS DA DOENÇA SOBRE A CLONAGEM DO EUCALIPTO ${ }^{1}$
}

\author{
Reginaldo Gonçalves Mafia ${ }^{2}$, Acelino Couto Alfenas ${ }^{3}$, Ricardo Miguel Penchel Filho ${ }^{4}$, Maria Alves \\ Ferreira $^{5}$ e Rafael Ferreira Alfenas ${ }^{6}$
}

\begin{abstract}
RESUMO - Este trabalho objetivou estudar a disseminação de Ralstonia solanacearum por meio de mudas e avaliar os efeitos da murcha-bacteriana sobre a produtividade na clonagem do eucalipto. Amostras de minicepas, miniestacas e mudas de sete clones foram avaliadas quanto à presença de infecções bacterianas. Em experimento específico, avaliou-se o substrato de enraizamento como fonte de inóculo do patógeno. Em intervalos mensais, determinaram-se o enraizamento médio e o índice de produtividade (IP), visando avaliar os efeitos da doença sobre a produtividade de minicepas. Constatou-se a presença do patógeno em minicepas de cinco clones, enquanto todas as mudas de todos os setes clones avaliados apresentaram a doença. Essa diferença comprovou que a disseminação do patógeno e a transmissão da doença ocorreram durante o processo de clonagem do eucalipto. O substrato de enraizamento foi eficiente para a sobrevivência do patógeno e como fonte de inóculo para a doença. As mudas sem sintomas e com infecções sistêmicas provaram o potencial de transmissão do patógeno para o campo no sistema de propagação clonal do eucalipto. Os estresses fisiológicos causados pelas infecções bacterianas reduziram quatro vezes o IP dos minijardins clonais. As medidas adotadas foram eficientes para a erradicação da doença no viveiro e para evitar a disseminação do patógeno para o campo.
\end{abstract}

Palavras-chave: Ralstonia solanacearum, Mudas clonais e Doença sistêmica.

\section{BACTERIAL WILT: PATHOGEN SPREAD AND DISEASE EFFECTS ON THE EUCALYPTUS CLONING}

\begin{abstract}
This work was aimed to study the Ralstonia solanacearum spread through clonal propagation and to evaluate the bacterial wilt effects on the productivity of cloning process. Samples of mini-stumps, mini-cuttings, and clonal seedlings of seven eucalyptus clones were evaluated regarding to bacterial infections. In a specific experiment, rooting substrate was evaluated to the source of pathogen inoculum. At monthly intervals, the rooting average and productivity index (IP) were determinate in order to evaluate the disease effects on the mini-stumps productivity. The bacterial pathogen was observed on mini-stumps of five clones, while the clonal seedlings of all seven clones showed the disease. This difference was shown to be related to pathogen spread and to disease transmission, which took place during the eucalyptus cloning process. The rooting substrate was efficient to bacterial pathogen survival and as inoculum source to the disease. The symptomless clonal seedlings with systemic infection proved the potential of pathogen transmission to the field in eucalyptus clonal propagation system. The physiologic stresses caused by bacterial infections reduced by four times the IP of mini-clonal hedges. The practices adopted were efficient to permit eradication of disease on the nursery and to avoid the pathogen spread to the field.
\end{abstract}

Keywords: Ralstonia solanacearum, Cloning seedlings and Systemic disease.

\footnotetext{
${ }^{1}$ Recebido em 02.05.2011 e aceito para publicação em 28.05.2012.

2 Fibria Celulose S.A., Centro de Tecnologia. E-mail: <rgoncalves@ fibria.com.br>.

${ }^{3}$ Universidade Federal de Viçosa, Departamento de Fitopatologia. E-mail: <aalfenas@ufv.br>.

${ }^{4}$ Fibria Celulose S.A., Centro de Tecnologia. E-mail: <rp@ fibria.com.br $>$.

${ }^{5}$ Universidade Federal de Lavras, Departamento de Fitopatologia. E-mail: <mariaferreira@ dfp.ufla.br>.

${ }^{6}$ Universidade Federal de Viçosa, Departamento de Fitopatologia. E-mail:<rafael.alfenas@ ufv.br>.
} 


\section{INTRODUÇÃO}

A murcha-bacteriana do eucalipto, causada por Ralstonia solanacearum (YABUUCHI et al., 1995), é uma doença de grande importância econômica e epidemiológica, em razão da natureza sistêmica das infecções, das perdas causadas em viveiro e no campo e das várias características do patossistema que dificultam o controle. Além disso, Raltonia solanacearum é considerada uma das bactérias fitopatogênicas mais importantes do mundo, em consequência dos grandes prejuízos causados, de sua ampla distribuição geográfica, da extensa gama de hospedeiros e da elevada variabilidade. Essa bactéria causa doença em mais de 200 espécies de plantas, englobando aproximadamente 50 famílias botânicas (HAYWARD, 2000; ÁLVAREZ et al., 2010). Em razão da sua importância, $R$. solanacearum foi um dos primeiros patógenos de plantas com o genoma totalmente sequenciado (DENNY, 2000; SALANOUBAT et al., 2002).

Há fortes evidências de que várias espécies florestais são hospedeiras de $R$. solanacearum. Contudo, relatos sobre o declínio de árvores são limitados. Em geral, os sintomas em plantas arbóreas infectadas englobam a murcha permanente, a descoloração interna do lenho e o bloqueio dos tecidos vasculares com massas de células bacterianas. Todavia, os sintomas típicos podem variar, dependendo da espécie hospedeira. Para eucalipto, os sintomas da doença em viveiro diferem do que ocorre no campo. Em minijardim clonal, a doença caracteriza-se por necrose foliar, escurecimento anelar ou completo do lenho, murcha e morte de minicepas. Os sintomas na parte aérea são similares à morte gradual de minicepas submetidas a podas drásticas ou com sistema radicular malformado (ALFENAS et al., 2006).

A disseminação de $R$. solanacearum em grandes distâncias pode ocorrer por material vegetal para plantio. Em pequenas distâncias, a bactéria pode ser disseminada por ferramentas e equipamentos utilizados durante as práticas agrícolas, por insetos e pelo próprio homem (HAYWARD, 1991). Todavia, em eucalipto a transmissibilidade do patógeno durante a propagação clonal ainda não foi comprovada, o que pode interferir nesse sistema de produção de mudas. Além disso, ainda não se conhecem os efeitos da doença sobre a clonagem em escala comercial. Assim, este trabalho objetivou comprovar a transmissão do patógeno por mudas clonais e quantificar os efeitos das infecções bacterianas sobre a produtividade de minijardins clonais de eucalipto.

\section{MATERIAL E MÉTODOS}

A quantificação e monitoramento da incidência de infecções do patógeno, bem como da produtividade de minicepas, foi realizado durante um ano, em viveiro comercial de produção de mudas de clones híbridos (E. urophylla Blake x E. grandis Hill ex Maiden) de eucalipto. Em contrapartida, a avaliação do substrato de enraizamento como fonte de inóculo foi realizada em experimento específico, realizado no viveiro de pesquisa do Departamento de Engenharia Florestal da Universidade Federal de Viçosa, em Viçosa, MG.

\subsection{Detecção do patógeno nas diferentes fases de produção de mudas}

Objetivou-se avaliar a transmissibilidade do patógeno por meio de brotações contaminadas. Para isso, empregou-se um protocolo de detecção da bactéria em minicepas, com ou sem sintomas, em miniestacas colhidas em três posições (basal, mediana e apical) da brotação da minicepa, em miniestaca na fase de enraizamento e em mudas aptas para expedição. A amostragem foi realizada ao acaso, totalizando 30 minicepas e mesmo número de miniestacas com ou sem sintomas da doença. Para rastrear a fonte de infecção do patógeno no viveiro, realizou-se uma amostragem de 50 mudas de cada um dos sete clones avaliados nas demais fases do processo de propagação clonal.

O protocolo de detecção utilizado consistiu no emprego do teste de exsudação em gota d'água. Para realização do teste, retiraram-se três fragmentos da região medular do coleto das minicepas e mudas ou da base das miniestacas, de aproximadamente $25 \mathrm{~mm}^{2}$ de área e espessura de $1 \mathrm{~mm}$. Esses fragmentos foram depositados em gotas de água que, após $1 \mathrm{~min}$, foram observadas ao microscópio de luz (40 e 100 X), para constatação de exsudação de pus bacteriano a partir de suas extremidades.

\subsection{Colonização bacteriana de mudas clonais}

A colonização bacteriana foi determinada em mudas com 90 dias de idade, dos sete clones avaliados anteriormente. Inicialmente, separou-se a parte aérea do sistema radicular, e em seguida retiraram-se as folhas 
e procedeu-se à remoção dos resíduos em água corrente. Com o auxílio de régua graduada, mediu-se o comprimento da haste, e retirou-se um fragmento de $1 \mathrm{~cm}$ de cada extremidade. Do restante foram retirados mais três fragmentos, de igual tamanho e em posições equidistantes. Os fragmentos obtidos após a determinação da massa fresca foram desinfestados superficialmente pela imersão em álcool $50 \%$ por 30 seg e em hipoclorito de sódio $5 \%$ por $1 \mathrm{~min}$. Posteriormente, removeu-se o excesso de cloro em água destilada esterilizada. Em condições assépticas, os fragmentos foram transferidos e macerados, separadamente e de forma manual, por 3 min, em eppendorfs contendo $1 \mathrm{ml}$ de água esterilizada. Em seguida, procedeu-se à agitação dos fragmentos em agitador Mini-Beadbeater a $1.500 \mathrm{rpm}$, por $40 \mathrm{seg}$. Do macerado dos três primeiros fragmentos, enumerados a partir da base da haste, foi transferida uma alíquota de $20 \mu \mathrm{l}$ para um poço de uma placa de teste Elisa contendo $180 \mu 1$ de água esterilizada. A suspensão obtida do primeiro fragmento foi submetida a três diluições $\left(10^{-1}\right.$, $10^{-2}$ e $\left.10^{-3}\right)$, a do segundo fragmento a duas diluições $\left(10^{-1}\right.$ e $\left.10^{-2}\right)$ e a do terceiro a apenas uma diluição $\left(10^{-1}\right)$. Quanto aos demais fragmentos, não foram realizadas diluições da suspensão obtida após a maceração e agitação dos fragmentos. Alíquotas de $10 \mu \mathrm{l}$ de cada diluição foram transferidas para meio de Kado e Heskett (1970) em placas de Petri. Após 24 h de incubação, a $28^{\circ} \mathrm{C}$ no escuro, quantificou-se o número de unidades formadoras de colônias (ufc). A colonização bacteriana foi expressa em ufc/g de tecido fresco. Para cada clone, empregaram-se 10 repetições, cada uma constituída de uma muda. Para cada fragmento foram realizadas cinco repetições de cada diluição. $\mathrm{O}$ experimento foi conduzido em delineamento inteiramente casualizado e em arranjo fatorial composto dos fatores clone e posição de retirada do fragmento.

\subsection{Substrato de enraizamento como fonte de inóculo}

Objetivou-se avaliar o substrato de enraizamento como fonte de inóculo de $R$. solanacearum. Para isso, um substrato de enraizamento constituído de casca de arroz carbonizada, vermiculita de granulometria média e composto de casca de pinus (1:1:1) foi infestado com o patógeno. O inóculo bacteriano foi produzido em meio sólido de Kado e Heskett (1970) a $28^{\circ} \mathrm{C}$. Após $48 \mathrm{~h}$ de incubação, procedeu-se à raspagem das colônias em solução salina ( $\mathrm{NaCl} 0,85 \%$ ), ajustando a concentração de inóculo por espectrofotometria $\left(\mathrm{OD}_{540}=0,2 \mathrm{Abs}\right)$ para aproximadamente $10^{8} \mathrm{ufc} / \mathrm{ml}$. A infestação do substrato foi realizada na proporção de $0,1 \mathrm{ml}$ de inóculo por $\mathrm{cm}^{3}$ de substrato. O substrato da testemunha foi umedecido com água esterilizada em igual proporção. Após essa etapa, o substrato foi utilizado para preenchimento de tubetes de $50 \mathrm{ml}$ de capacidade, os quais foram dispostos em bandejas. Em seguida, estacas de cinco clones de eucalipto (E. urophylla $\times$ E.grandis) com aproximadamente $10-12 \mathrm{~cm}$ de comprimento foram colhidas de minijardim clonal e postas para enraizar sob nebulização intermitente de água. Após 30 dias, realizou-se a avaliação do número de estacas enraizadas e da incidência da bactéria (método de detecção descrito anteriormente) em estacas não enraizadas. As mudas foram aclimatadas à sombra (50\%) por 30 dias e avaliadas aos 30 dias após a aclimatação, quanto à presença de infecções bacterianas. O experimento foi conduzido em delineamento inteiramente casualizado com seis repetições de 20 estacas por tratamento e para cada clone.

\subsection{Enraizamento e índice de produtividade de minicepas doentes}

Emintervalos mensais e durante um ano, determinou-se o enraizamento médio nos três últimos meses desse período, bem como se calculou o índice de produtividade (IP), definido pelo produto entre o enraizamento médio e o número de miniestacas produzido por minicepa. O monitoramento foi realizado em sete clones de eucalipto, estabelecidos em minijardins distintos. As avaliações foram realizadas por senso em todo o minijardim e em todos os lotes de produção de mudas.

\subsection{Análises estatísticas}

Os dados dos experimentos sobre colonização bacteriana e do substrato de enraizamento como fonte de inóculo foram submetidos, separadamente, à análise de variância (ANOVA), empregando-se o teste F a $5 \%$ de probabilidade. Posteriormente, a comparação entre as médias das variáveis qualitativas foi realizada pelo teste de Tukey $(p<0,05)$. As análises estatísticas foram realizadas com o auxílio do programa SAEG(EUCLYDES, 1997).

\section{RESULTADOS}

\subsection{Detecção do patógeno nas diferentes fases de produção de mudas}

Entre os setes clones avaliados, o patógeno não foi detectado apenas nos clones C1 (Minijardim 1) e C3 (Minijardins 4 e 9). Nos demais, independentemente

Revista Árvore, Viçosa-MG, v.36, n.4, p.593-602, 2012 
da existência de sintomas externos, comprovou-se a presença de infecções bacterianas, porém, geralmente, com menor incidência nas minicepas sem sintomas (Tabela 1).

Os resultados evidenciaram menor incidência de infecções em miniestacas coletadas a partir de minicepas assintomáticas, principalmente na parte apical da brotação. Em minicepas sintomáticas, em geral houve redução gradual na incidência da doença da base para o ápice da brotação (Tabela 1).

Miniestacas não enraizadas, coletadas na casa de enraizamento, evidenciaram a presença do patógeno em todos os clones amostrados, com $100 \%$ de incidência nos clones C2, C4 e C5 (Tabela 2). Analogamente, houve exsudação bacteriana a partir de mudas de todos os clones avaliados. A menor intensidade da doença foi

Tabela 1 - Incidência e sintomas da murcha-bacteriana em minicepas e miniestacas de eucalipto.

Table 1 - Incidence and symptoms of bacterial wilt on the mini-stumps and mini-cuttings from eucalyptus.

\begin{tabular}{|c|c|c|c|c|c|c|}
\hline Clone & Minijardim & $\begin{array}{l}\text { Data de } \\
\text { plantio }\end{array}$ & $\begin{array}{c}\text { Presença de } \\
\text { sintomas }\end{array}$ & $\begin{array}{c}\text { Incidência } \\
\text { da doença }(\%)\end{array}$ & $\begin{array}{l}\text { Terço da } \\
\text { minicepa }\end{array}$ & $\begin{array}{c}\text { Incidência } \\
\text { miniestacas (\%) }\end{array}$ \\
\hline $\mathrm{C} 1$ & 01 & $04 / 10 / 04$ & Ausente & 0,0 & - & 0,0 \\
\hline \multirow[t]{6}{*}{$\mathrm{C} 2$} & 02 & $28 / 10 / 04$ & Ausente & 86,7 & Basal & 10,0 \\
\hline & & & & & Mediano & 0,0 \\
\hline & & & & & Apical & 10,0 \\
\hline & & & Presente & 86,7 & Basal & 70,0 \\
\hline & & & & & Mediano & 60,0 \\
\hline & & & & & Apical & 50,0 \\
\hline \multirow[t]{6}{*}{$\mathrm{C} 2$} & 03 & $11 / 11 / 04$ & Ausente & 96,7 & Basal & 30,0 \\
\hline & & & & & Mediano & 10,0 \\
\hline & & & & & Apical & 30,0 \\
\hline & & & Presente & 93,3 & Basal & 90,0 \\
\hline & & & & & Mediano & 70,0 \\
\hline & & & & & Apical & 60,0 \\
\hline C3 & 04 & $13 / 10 / 03$ & Ausente & 0,0 & - & 0,0 \\
\hline $\mathrm{C} 3$ & 09 & $07 / 10 / 03$ & Ausente & 0,0 & - & 0,0 \\
\hline \multirow[t]{6}{*}{$\mathrm{C} 4$} & 06 & $23 / 02 / 05$ & Ausente & 46,7 & Basal & 20,0 \\
\hline & & & & & Mediano & 0,0 \\
\hline & & & & & Apical & 0,0 \\
\hline & & & Presente & 100,0 & Basal & 70,0 \\
\hline & & & & & Mediano & 60,0 \\
\hline & & & & & Apical & 30,0 \\
\hline \multirow[t]{6}{*}{$\mathrm{C} 4$} & 10 & 29/09/04 & Ausente & 83,3 & Basal & 20,0 \\
\hline & & & & & Mediano & 10,0 \\
\hline & & & & & Apical & 0,0 \\
\hline & & & Presente & 93,3 & Basal & 70,0 \\
\hline & & & & & Mediano & 70,0 \\
\hline & & & & & Apical & 60,0 \\
\hline \multirow[t]{6}{*}{ C5 } & 08 & $09 / 12 / 04$ & Ausente & 86,7 & Basal & 10,0 \\
\hline & & & & & Mediano & 20,0 \\
\hline & & & & & Apical & 0,0 \\
\hline & & & Presente & 93,3 & Basal & 90,0 \\
\hline & & & & & Mediano & 80,0 \\
\hline & & & & & Apical & 60,0 \\
\hline \multirow[t]{6}{*}{ C6 } & 11 & $30 / 12 / 04$ & Ausente & 73,3 & Basal & 10,0 \\
\hline & & & & & Mediano & 0,0 \\
\hline & & & & & Apical & 0,0 \\
\hline & & & Presente & 93,3 & Basal & 90,0 \\
\hline & & & & & Mediano & 70,0 \\
\hline & & & & & Apical & 80,0 \\
\hline
\end{tabular}

Revista Árvore, Viçosa-MG, v.36, n.4, p.593-602, 2012 
observada nos clones $\mathrm{C} 1$ e C 3 , nos quais não foram constatadas infecções em minicepas. Os clones mais afetados foram o C2 e C6 (Tabela 2).

\subsection{Colonização bacteriana de mudas clonais}

Não houve diferença entre os clones avaliados quanto à extensão de colonização, sendo, em geral, a presença da bactéria observada em até $25 \%$ da altura total da muda, a partir da região do coleto. Todavia, houve diferença entre os clones quanto à colonização bacteriana, que em média variou de $7 \times 10^{3}$ a $2,7 \times 10^{6}$ ufc/g de tecido fresco. Os clones com menor colonização foram o $\mathrm{C} 1, \mathrm{C} 3$ e $\mathrm{C} 7$ e os com maior nível populacional da bactéria nos tecidos, o C2, C4 e C6 (Figura 1).

Tabela 2 - Incidência da murcha-bacteriana em miniestacas sem raízes e em mudas de eucalipto.

Table 2 -Incidence of bacterial wilt on the mini-cuttings without roots and eucalyptus seedlings.

\begin{tabular}{cccc}
\hline \multirow{2}{*}{ Clone } & \multirow{2}{*}{ Minijardim } & \multicolumn{2}{c}{ Incidência (\%) } \\
\cline { 3 - 4 } & & Miniestacas & Mudas \\
\hline C1 & 01 & - & 40 \\
C2 & 02 & 100 & 90 \\
C2 & 03 & 100 & - \\
C3 & 04 & - & 30 \\
C4 & 06 & 60 & 60 \\
C4 & 10 & 100 & - \\
C5 & 08 & 100 & 80 \\
C6 & 11 & 80 & 90 \\
C7 & - & - & 70 \\
\hline
\end{tabular}

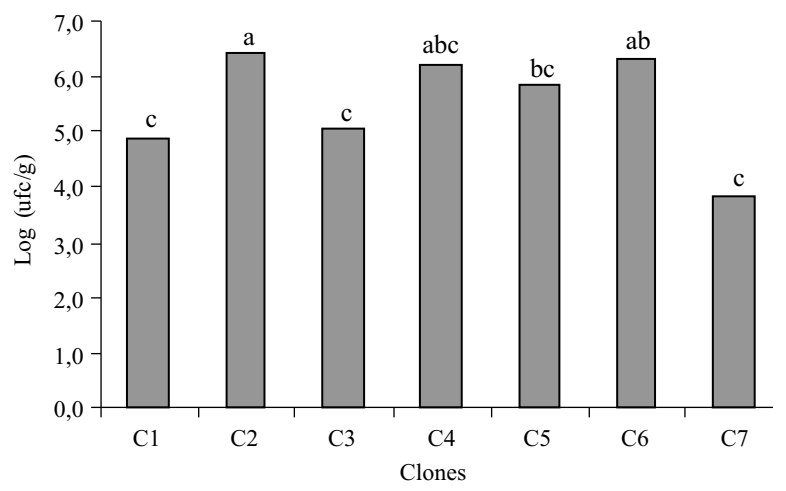

Figura 1 - População bacteriana em tecidos de clones de eucalipto. Colunas sob a mesma letra não diferem entre si, estatisticamente, pelo teste de Tukey $(\mathrm{p}<0,05)$.

Figure 1 -Bacterial population on eucalyptus clones tissue. Columns under the same letter do not differ statistically by the Tukey's test $(p<0,05)$.

\subsection{Substrato de enraizamento como fonte de inóculo}

O índice de enraizamento variou em razão da presença ou ausência da bactéria no substrato. Diferentemente do clone UFV 03, os clones UFV 02, UFV 04 e UFV 05 apresentaram menor enraizamento em substrato infestado. No clone UFV 01, não houve diferença quanto ao enraizamento das mudas produzidas em substrato infestado ou não com o patógeno. A frequência de infecções bacterianas variou entre 80 e $98 \%$ em miniestacas não enraizadas. Nas mudas obtidas, a incidência da doença chegou a $100 \%$ no clone UFV 02 (Tabela 3).

\subsection{Enraizamento e índice de produtividade de minicepas doentes}

O enraizamento médio variou em razão da época e do clone de eucalipto, e a partir do mês de novembro houve redução acentuada do índice, principalmente em cinco dos sete clones avaliados. Nos clones $\mathrm{C} 1$ e C3, cujas minicepas se encontravam livres da doença, não houve diminuição do enraizamento. Entre fevereiro e outubro, o índice de enraizamento variou entre 60 e $90 \%$. No final do período monitorado, o índice de enraizamento foi de 15, 17 e $19 \%$ nos clones C2, C4 e C7, respectivamente (Figura 2A).

Conforme ocorreu no enraizamento, o índice de produtividade foi menor nos clones sabidamente infectados pelo patógeno no minijardim. Ao final do período de monitoramento, nos clones mais afetados (C2, C4 e C7) houve diminuição de até quatro vezes do índice de produtividade (Figura 2B).

Tabela 3 -Enraizamento médio (E), porcentagem de miniestacas não enraizadas (ENE) e de mudas assintomáticas (MA) com presença de infecções bacterianas.

Table 3 -Average rooting (E), percentage of mini-cuttings without roots (ENE), and seedlings symptomless (MA) with bacterial infections.

\begin{tabular}{lcccc}
\hline \multirow{2}{*}{ Clone } & \multicolumn{2}{c}{ E (\%) } & & \\
\cline { 2 - 3 } & Testemunha & Infestado & & \\
\hline UFV 01 & $9,4^{\mathrm{ns}}$ & 10,4 & 79,8 & 87,5 \\
UFV 02 & $69,8^{*}$ & 20,8 & 86,2 & 100 \\
UFV 03 & $11,4^{*}$ & 43,8 & 98,3 & 93,5 \\
UFV 04 & $68,7^{*}$ & 21,9 & 89,5 & 87,5 \\
UFV 05 & $32,3^{*}$ & 13,5 & 92,9 & 60,0 \\
\hline
\end{tabular}

ns $\mathrm{e} *$ Comparações entre as médias de enraizamento de um mesmo clone não significativas $\left({ }^{\mathrm{ns}}\right)$ ou significativas $(*)$ a $5 \%$ de probabilidade, pelo teste $t$.

Revista Árvore, Viçosa-MG, v.36, n.4, p.593-602, 2012 

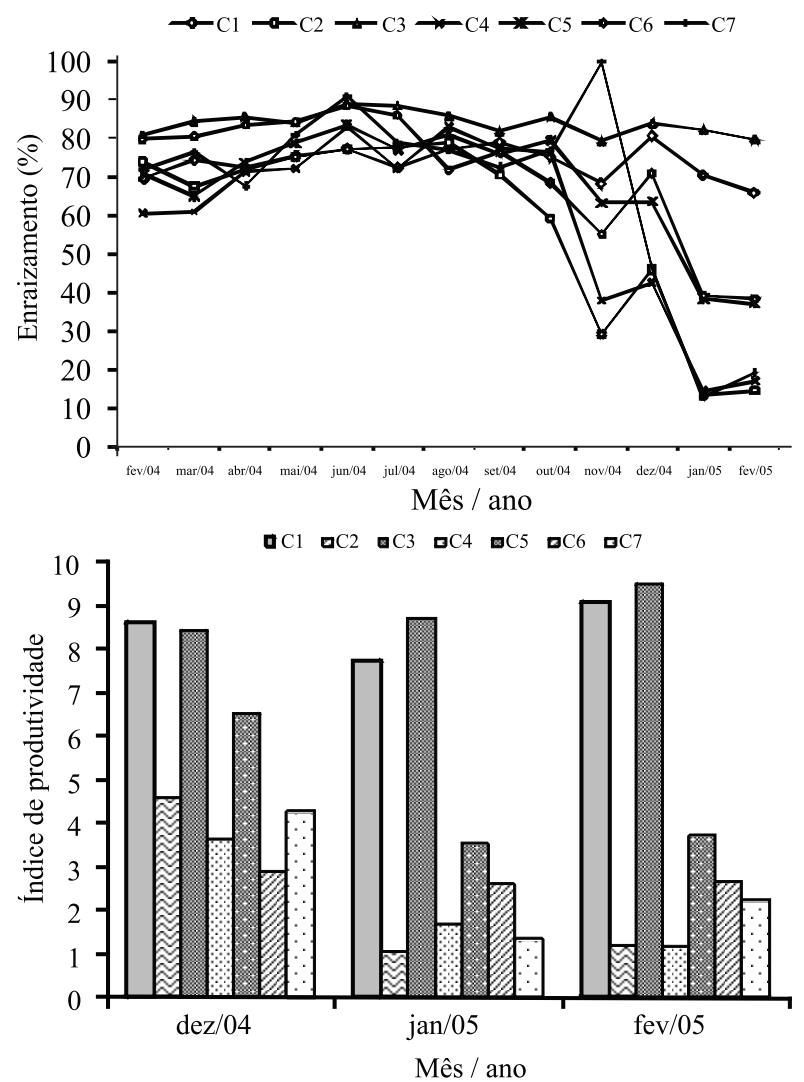

Figura 2 - Enraizamento médio (A) e índice de produtividade (B) de sete clones de eucalipto.

Figure 2 -Average rooting (A) and productivity index (B) of seven eucalyptus clones.

\section{DISCUSSÃO}

Os resultados deste trabalho evidenciaram que não existe correlação entre a presença de infecções sistêmicas e a manifestação de sintomas externos da doença. As mudas aptas para plantio de diferenrtes clones, mesmo com colonização de $25 \%$ da parte aérea, não apresentaram o sintoma marcador de murcha. Esses resultados apontaram para um risco de introdução involuntária do patógeno, seja em viveiro, seja em campo, por meio de mudas contaminadas e assintomáticas. Aparentemente, a murcha-bacteriana apresenta desenvolvimento lento em eucalipto, cuja colonização do patógeno e expressão dos sintomas parecem depender muito das condições de ambiente e da predisposição ou debilitação fisiológica do hospedeiro. Em minijardim clonal, é possível que os sintomas externos da doença sejam expressos somente em períodos mais quentes do ano, em minicepas submetidas a coletas intensas de brotações e, ou, com sistema radicular malformado.

A população bacteriana em mudas de eucalipto foi de $7 \times 10^{3}$ a $2,7 \times 10^{6} \mathrm{ufc} / \mathrm{g}$ de tecido fresco, o que é inferior ao normalmente encontrado em outras plantas hospedeiras. Em tomateiro, por exemplo, nos vasos do xilema a população bacteriana atinge rapidamente níveis populacionais superiores a $10^{10} \mathrm{ufc} / \mathrm{g}$ de tecido fresco, concomitantemente com o aparecimento do sintoma de murcha, seguido da morte da planta (GENIN; BOUCHER, 2002; DENNY, 2000). Em eucalipto, além da baixa população bacteriana, observou-se pequena frequência de murcha e de morte das plantas infectadas, o que pode estar relacionado com as diferenças de constituição da parede celular de plantas lenhosas em relação às plantas arbustivas.

A produção de mudas de eucalipto, por meio da miniestaquia, apresenta inúmeras vantagens econômicas e operacionais. Contudo, ficou comprovado que, por esse sistema de produção, $R$. solanacearum é facilmente multiplicada e transmitida para as mudas, a partir da coleta e enraizamento de miniestacas infectadas, colhidas de minicepas doentes assintomáticas. Adicionalmente, existe o risco de contaminação dos propágulos vegetativos ao longo do processo de produção de mudas. Essa última hipótese foi confirmada pelos resultados obtidos quanto à avaliação do substrato de enraizamento como fonte de inóculo e pela presença de mudas doentes dos clones $\mathrm{C} 1$ e C3, propagadas a partir de minicepas sadias. No primeiro caso, acredita-se que o patógeno foi capaz de infectar as miniestacas a partir de sua base, que apresenta grande área para penetração da bactéria. Nos clones livres da doença no minijardim, acredita-se que as mudas tenham apresentado a enfermidade, mesmo que em menor intensidade (30 a 40\%), em razão da contaminação das miniestacas. Essas contaminações podem ter ocorrido pelo uso de tesouras de poda infestadas com o patógeno ou pelo armazenamento dos propágulos vegetativos em recipientes contaminados.

Na área florestal, ainda são escassos os estudos sobre transmissão de doenças vasculares por ferramentas de poda. No entanto, para culturas agrícolas em ambiente protegido, sabe-se que as medidas de sanitização são importantes no manejo integrado, considerando diferentes patossistemas. Vida et al. (2004) observaram 
que a desinfestação de tesouras de poda, em hipoclorito de sódio $2 \%$, resultou em controle satisfatório da podridão gomosa em cultivo do melão rendilhado. Com base em informações em outros patossistemas, em geral temperaturas acima de $90^{\circ} \mathrm{C}$, por no mínimo $3 \mathrm{seg}$, têm resultado em controle de vários patógenos (EHRET et al., 2001; RUNIA et al., 1988). Assim, é recomendável desinfestar as tesouras e recipientes utilizados durante o preparo de miniestacas para enraizamento. O binômio letal para erradicação de $R$. solanacearum foi estimado previamente em 85 a $90^{\circ} \mathrm{C}$, por pelo menos $30 \mathrm{seg}$ (dados não publicados).

De forma geral, observou-se menor incidência de infecções bacterianas em miniestacas apicais, principalmente em propágulos coletados de minicepas sem sintomas externos da doença. O objetivo inicial desta avaliação foi determinar se na posição apical das brotações seria possível obter propágulos livres da doença. Pelos resultados, ficou comprovado que não existe garantia da sanidade de miniestacas, mesmo em coletas apicais a partir de minicepas doentes. Desse modo, o mais seguro é realizar a limpeza clonal a partir de técnicas de micropropagação, preferencialmente em meios de cultivo sem antibióticos, a fim de evidenciar possíveis contaminações bacterianas. Além disso, é importante considerar que existem bactérias endofíticas e rizobactérias em eucalipto (MAFIA et al., 2009), as quais podem ser confundidas com $R$. solanacearum.

A colonização bacteriana em mudas variou em função do clone de eucalipto, o que pode estar relacionado, principalmente, com o nível de resistência e com o tempo de colonização. Assim, em trabalhos futuros torna-se necessário avaliar essas hipóteses. Avaliações do nível de resistência para eucalipto, devido à natureza sistêmica da doença, têm sido realizadas de forma qualitativa (DIANESE; DRISTIG, 1993; LI e WU, 1996). Todavia, acredita-se que seja possível melhorar os protocolos de avaliação, tornando as avaliações quantitativas, considerando outros exemplos de doenças do eucalipto (XAVIER et al., 2007).

As recentes constatações da murcha-bacteriana em viveiros clonais em várias regiões do país indicam que a água, a areia e, ou, as próprias mudas podem constituir fontes potenciais de inóculo primário na formação e manejo de minijardins clonais. Como se sabe, os sistemas hidropônicos, os quais são similares aos minijardins em leito de areia, com frequentes fertirrigações, são favoráveis para a disseminação de vários patógenos (SAVVAS, 2003; EHRET et al., 2001; MAFIA et al., 2008). Para minijardins clonais de eucalipto, considerando a inexistência de métodos para o controle curativo da murcha- bacteriana, é fundamental prevenir a introdução do patógeno no sistema. Para estabelecimento dos canaletões, acredita-se que, idealmente, a areia deve ser desinfestada ou proveniente de jazidas, em detrimento de areia extraída de rios ou de outros mananciais a céu aberto. Além disso, as minicepas devem ser formadas a partir de mudas livres da bactéria, preferencialmente micropropagadas por técnicas de cultura de tecidos. Outro ponto importante é utilizar água livre de inóculo, preferencialmente captada de poços artesianos ou previamente tratada.

Embora não tenham sido estudadas neste trabalho, é possível que plantas daninhas, naturalmente presentes em viveiros clonais de eucalipto, sejam também importantes fontes de inóculo. $R$. solanacearum pode sobreviver por longos períodos, na forma de células viáveis, mas não cultiváveis (GREY; STECK, 2001), em associação com a matéria orgânica e com plantas daninhas. Todavia, ainda hoje existe pouca informação acerca das espécies botânicas hospedeiras (QUEZADOSOARES; LOPES, 1994). Quanto aos níveis de suscetibilidade, as plantas daninhas podem ser altamente suscetíveis e evidenciar sintomas típicos de murchabacteriana, como no caso de Crassocephalum crepidioides (Benth) S. Moore (Asteraceae) ou tolerantes, com expressão de poucos sintomas da doença, como Portulaca oleracea L. (Portulacaceae). Ainda existem evidências de hospedeiras, que sob determinadas condições permanecem assintomáticas ou com leves sintomas de infecção, como Solanum carolinense L. (TUSSIME, 1997). Ademais, em certas plantas daninhas observam-se variações quanto ao aparecimento de sintomas (MIRANDA et al., 2004). Como medida preventiva, é importante eliminar constantemente as plantas daninhas dos viveiros, independentemente da espécie e, especialmente, nos canaletões dos minijardins clonais.

Ralstonia solanacearum pode ser disseminada dentro e entre países por solo, água e material para plantio com infecção latente (HAYWARD, 1991). Entre viveiros comerciais de eucalipto, é comum a permuta de material genético, o que aumenta o risco de introdução do patógeno de um viveiro para outro. Nesse sentido, é importante estabelecer protocolos de detecção da bactéria para certificação da sanidade de mudas clonais de eucalipto, bem como para substrato de enraizamento, uma vez que se comprovou que esse tipo de insumo

Revista Árvore, Viçosa-MG, v.36, n.4, p.593-602, 2012 
pode funcionar como fonte de inóculo. Existem várias técnicas para detecção de $R$. solanacearum em material vegetal e em solo. A técnica mais comum, mas menos sensível, consiste no cultivo do patógeno em meio de cultura seletivo (ENGELBRECHT, 1994). Outras técnicas ainda incluem o uso de métodos sorológicos (ELISA ou imunufluorescência) (ROBINSON, 1993) ou testes de patogenicidade em plantas hospedeiras (GRAHAM; LLOYD, 1978). Geralmente, essas técnicas são inadequadas, em termos de especificidade, sensibilidade de detecção e do tempo necessário, especialmente para detecção da bactéria a partir do solo. Entretanto, a amplificação de DNA oferece diversas vantagens em relação às técnicas clássicas (POUSSIER et al., 2002). Vários protocolos de Polymerase Chain Reaction (PCR) e diferentes oligonucleotídeos a partir das regiões $16 \mathrm{~S}$ e $23 \mathrm{~S}$ rRNA têm sido descritos para diagnose e, ou, identificação de $R$. solanacearum (PASTRIK; MAISS, 2000; POUSSIER; LUISETTI, 2000; WELLER et al., 2000; OEPP/EPPO, 2004), os quais podem ser utilizados para detecção do patógeno a partir de diferentes substratos naturais, incluindo água, solo, semente e plantas (POUSSIER et al., 2002; CARUSO et al., 2003).

Em minijardim clonal, além da manutenção de alta umidade da areia nos leitos dos canaletões, decorrente das frequentes fertirrigações, ficou evidenciada a ocorrência de altas temperaturas na superfície da areia, em torno de $56^{\circ} \mathrm{C}$ (dados não publicados). Em geral, temperaturas superiores a $46^{\circ} \mathrm{C}$ causam injúrias em raízes finas e em pelos absorventes, podendo favorecer a penetração de $R$. solanacearum, por meio de ferimentos e nos locais de emergência de raízes secundárias. Após a penetração, a bactéria coloniza os espaços intercelulares do córtex da raiz e do parênquima vascular, culminando com a desestruturação das paredes celulares, o que facilita, em uma segunda etapa, a disseminação pelo sistema radicular (VASSE et al., 1995). A temperatura foliar em minicepas doentes foi cerca de $2^{\circ} \mathrm{C}$ acima da média de minicepas sadias (dados não publicados). Nesse caso, acredita-se que a obstrução dos vasos condutores pelas células bacterianas reduz o fluxo ascendente de água e, consequentemente, a eficiência do processo de resfriamento via transpiração foliar. Essa hipótese deve ser comprovada em estudos futuros. Todavia, acredita-se que essa seja a explicação fisiológica para o surgimento de lesões foliares em plantas doentes com infecções confinadas ao sistema vascular.
Em razão da constatação da doença em todas as fases de produção de mudas, uma série de medidas foi implantada visando erradicar o patógeno do viveiro onde a murcha-bacteriana foi diagnosticada, pela primeira vez no Brasil, por esse autor. As mudas, minicepas e propágulos vegetativos foram eliminados, além da areia de minijardim e substrato de enraizamento. As estruturas do viveiro, as ferramentas e os equipamentos foram desinfestados. Essas medidas foram eficientes e resultaram na erradicação do patógeno do viveiro, conforme constando em avaliações posteriores, comprovando a eficiência dos procedimentos adotados no manejo da murcha-bacteriana em viveiros de eucalipto.

\section{CONCLUSÕES}

Neste trabalho, comprovou-se a disseminação de $R$. solanacearum por meio de mudas clonais, a partir de duas fontes de inóculo, ou seja, brotações de minicepas doentes e substrato de enraizamento. Além disso, foi possível quantificar os efeitos das infecções bacterianas sobre a clonagem do eucalipto em escala comercial. De forma geral, a doença diminuiu em quatro vezes a produtividade dos minijardins clonais, afetando de forma irreversível a qualidade e inviabilizando o aproveitamento das mudas produzidas, em razão do risco de disseminação do patógeno para o campo.

\section{REFERÊNCIAS}

ALFENAS, A. C. et al. Ralstonia solanacearum em viveiros clonais de eucalipto no Brasil. Fitopatologia Brasileira, v.31, n.4, p.357-366, 2006.

ÁLVAREZ, B.; BIOSCA, E. G.; LÓPEZ, M. M. On the life of Ralstonia solanacearum, a destructive bacterial plant pathogen. In: MÉNDEZ VILAS, A. (Ed.). Current research, technology and education topics in applied microbiology and microbial biotechnology. Formatex: 2010. v.1. p.267-279.

CARUSO, P. et al. A new sensitive cooperational polymerase chain reaction for rapid detection of Ralstonia solanacearum in water. Journal of Microbiological Methods, v.55, n.1, p.257-272, 2003.

DENNY, T. P. Ralstonia solanacearum - a plant pathogen in touch with its host. Trends in Microbiology, v.8, n.11, p.486-489, 2000. 
DIANESE, J. C.; DRISTING, M. C. G. Screening Eucalyptus selections for resistance to bacterial wilt caused by Pseudomonas solanacearum. In: HARTMAN, G. L.; HAYWARD, A. C. (Eds.). Bacterial Wilt. Proceedings of an International Conference. Kaoshiung: ACIAR Proc., 1993. p.206-210. v.45.

EHRET L. D. et al. Disinfestation of recirculating nutrient solutions in greenhouse horticulture. Agronomie, v. 21, n. 4, p. 323-339, 2001.

ENGELBRECHT, M. C. Modification of a semi selective medium for isolation and quantification of Pseudomonas solanacearum. ACIAR

Bacterial Wilt Newsletter, v.10, p.3-5, 1994.

EUCLYDES, R. F. Manual de utilização do programa SAEG (Sistema para Análises Estatística e Genética). Viçosa, MG: Universidade Federal de Viçosa, 1997. 150p.

GENIN, S.; BOUCHER, C. Ralstonia

solanacearum: secrets of a major pathogen unveiled by analysis of its genome. Molecular Plant Pathology, v.3, n.3, p.111-118, 2002.

GRAHAM, J.; LLOYD, A. B. An improved indicator plant method for the detection of Pseudomonas solanacearum race 3 in soil. Plant Disease Report, v.62, p.35-37, 1978.

GREY, B. E.; STECK, T. R. The viable but nonculturable state of Ralstonia solanacearum may be involved in long-term survival and plant infection. Applied Environmental Microbiology, v.67, n.9, p.3866-3872, 2001.

HAYWARD, A. C. Biology and epidemiology of bacterial wilt caused by Pseudomonas solanacearum. Annual Review

Phytopathology, v.29, n.1, p.65-87, 1991.

HAYWARD, A. C. Ralstonia solanacearum. In: LEDERBERG, J. (Ed.). Encyclopedia of Microbiology. San Diego: Academic Press, 2000. p.32-42. v.4.

KADO, E. I.; HESKETT, M. G. Selective media for isolation of Agrobacterium, Corynebacterium, Erwinia, Pseudomonas and Xanthomonas.

Phytopathology, v.60, n.6, p.969-976, 1970.
LI, H.; WU, X. Y. The current status, causes and control of forest diseases in Haiman province. Tropical Forestry, v.24, p.101-103, 1996.

MAFIA, R. G. et al . Microbiolização e interação entre rizobactérias promotoras do crescimento e clones de eucalipto. Revista Árvore, v.33, n.5, p.789-797, 2009.

MAFIA, R. G. et al. Reuse of untreated irrigation water as a vehicle of inoculum of pathogens in eucalyptus clonal nursery. Tropical Plant Pathology, v.33, n.2, p.96-102, 2008.

MIRANDA, E. F. O.; TAKATSU, A.; UESUGI, C. H. Colonização de raízes de plantas daninhas cultivas in vitro e em vasos por Ralstonia solanacearum, biovares 1, 2 e 3. Fitopatologia Brasileira, v.29, n.2, p.121-127, 2004.

ORGANISATION EUROPÉENNE POUR LA PROTECTION DES PLANTES/EUROPEAN PLANT PROTECTION ORGANISATION - OEPP/EPPO.

Ralstonia solanacearum. Diagnostic protocols for regulated pests. OEPP/EPPO Bulletin, v.34, p.173-178, 2004.

PASTRIK, K. H.; MAISS, E. Detection of Ralstonia solanacearum in potato tubers by polymerase chain reaction. Journal of Phytopathology, v.148, p.619-626, 2000.

POUSSIER, S. et al. Evaluation of procedures for reliable PCR detection of Ralstonia solanacearum in common natural substrates. Journal of Microbiological Methods, v.51, n.3, p.349-359, 2002.

POUSSIER, S.; LUISETTI, J. Specific detection of biovars of Ralstonia solanacearum in plant tissue by nested PCR. European Journal of Plant Pathology, v.106, n.3, p.255-265, 2000.

QUEZADO-SOARES, A. M.; LOPES, C. A. Murcha bacteriana (Pseudomonas solanacearum) em duas espécies de plantas daninhas da família Labiatae. Fitopatologia Brasileira, v.19, p.581-584, 1994.

ROBINSON, A. Serological detection of Pseudomonas solanacearum by ELISA. In: HARTMAN, G. L.; HAYWARD, A. C. (Eds.). INTERNATIONAL BACTERIAL WILT SYMPOSIUM, 1993, Kaohsiung. Proceedings... Canberra: ACIAR, 1993. p.28-31.

Revista Árvore, Viçosa-MG, v.36, n.4, p.593-602, 2012 
RUNIA W. T.; VAN OS, E. A.; BOLLEN G. J.

Disinfection of drainwater from soilless cultures by heat treatment. Netherlands Journal of Agriculture Science, v.36, p.231-238, 1988.

SALANOUBAT, M. et al. Genome sequence of the plant pathogen Ralstonia solanacearum.

Nature, v.415, n.6871, p.497-502, 2002.

SAVVAS, D. Hydroponics: A modern technology supporting the application of integrated crop management in greenhouse. Food, Agriculture e Environment, v.1, p.80-86, 2003.

TUSSIME, G. et al. Weeds as latent hosts of Ralstonia solanacearum in highland Uganda: Implications for lowland potato bacterial wilt control. In: INTERNATIONAL BACTERIAL WILT SYMPOSIUM, 2., Antilles Françaises, 1997. Proceedings... Guadaloupe: 1997.

VASSE, J.; FREY, P.; TRIGALET, A. Microscopic studies of intercellular infection and protoxylem invasion of tomato roots by Pseudomonas solanacearum. Molecular Plant-Microbe Interaction, v. 8, p.241-251, 1995.
VIDA, B. J. et al. Controle da podridão gomosa em melão rendilhado em cultivo protegido por sanitização de ferramenta de poda. Fitopatologia Brasileira, v.29, p.626-630, 2004.

WELLER, S. A. et al. Detection of Ralstonia solanacearum strains with a quantitative, multiplex, real-time, fluorogenic PCR (TaqMan) assay. Applied Environmental Microbiology, v.66, n.7, p.2853-2858, 2000.

XAVIER, A. A. et al. Resitência de Eucalyptus globulus e Eucalyptus nitens à ferrugem (Puccinia psidii). Revista Árvore, v.31, n.4, p.731-735. 2007.

YABUUCHI, E. et al. Transfer of two Burkholderia and an Alcaligenes species to Ralstonia gen. nov.: proposal of Ralstonia pickettii (Ralston, Palleroni and Douderoff 1973) comb. nov., Ralstonia solanacearum (Smith, 1896) comb. nov. \& Ralstonia eutropha (Davis, 1969) comb. nov. Microbiology and Immunology, v.39, n.11, p.897-904, 1995. 